\title{
La laguna enterrada y los ríos invisibles: imágenes del agua de la Ciudad de México en la obra poética de José Emilio Pacheco
}

\author{
Elisa T. Di Biase CASTRO \\ Departamento de Filología Románica \\ Universidad Complutense de Madrid \\ elisadibiase@gmail.com
}

Recibido: $12 / 09 / 2012$

Modificado: $19 / 05 / 2013$

Aceptado: $21 / 05 / 2013$

\section{Resumen}

Las aguas enterradas de la Ciudad de México, sus ríos ahora invisibles y la ciudad acuática que fue en los tiempos prehispánicos y que recordaba a los cronistas la imagen de Venecia, parecen subyacer a la ciudad moderna y resurgir en imágenes a manera de fantasmas. El agua, enterrada viva, atormenta con su presencia nostálgica y terrorífica a José Emilio Pacheco, poeta fuertemente ligado vital y literariamente a la urbe que lo vio nacer, pero, a la vez, con su eterna permanencia, simboliza para el autor obsesionado con el tema del tempus irreparabile fugit, el ciclo sin fin de la vida que salva a la ciudad del transcurrir y la destrucción inminente, que la lleva a renacer y reverdecer de manera constante, eternamente reflejada en las imágenes de sus mitos fundacionales, que parecen residir, como si se tratara de un útero oculto, en el agua desaparecida.

Palabras clave: Ciudad de México, José Emilio Pacheco, agua, mito, fantasma.

Title: The Buried Lagoon and the Invisible Rivers: Images of Mexico City's Water in José Emilio Pacheco's Poetry

\section{Abstract}

The buried waters of Mexico City, its now invisible rivers and the watery city it once was -which reminded the Spanish conquerors the image of Venice-, seem to underlie the modern metropolis and to resurge as phantoms. The water, buried alive, haunts José Emilio Pacheco with its nostalgic and terrifying presence. The life and literary work of this author are closely tied to the city where he was born. At the same time, these waters, with their eternal remaining, symbolize for the author, obsessed with the theme of tempus irreparabile fugit, the endless cycle of life that saves the city from passing and imminent destruction; the process which takes it to be constantly reborn, endlessly reflected on the images of its founding myths as if those resided in the uterus of the disappeared waters.

Keywords: Mexico City, José Emilio Pacheco, water, myth, phantom. 
Haber nacido en 1939, quizás el año más aciago del siglo XX, no es la única marca apocalíptica que pesa sobre José Emilio Pacheco, al que la fortuna también llevó a ver la luz en la Ciudad de México, urbe a la que estará íntima, esencial y casi fatalmente vinculado a lo largo de toda su trayectoria vital y literaria.

Discreto siempre en cuanto a su papel de escritor, Pacheco es, quizás, el poeta vivo de mayor trascendencia en México y uno de los más grandes de la lengua española -aunque su reticencia a creer en la importancia del autor seguramente le haría renegar de estas palabras. No conforme con esto, se ha desarrollado paralelamente en los más variados géneros literarios -el cuento, la novela, la traducción, el ensayo, el guión cinematográfico- e incluso ha inventado el término "aproximación", que es una versión libre y personal de otro texto.

La notable erudición de este autor, junto con su talento, le valieron desde muy joven un lugar en las letras mexicanas. En la década de los cincuenta, cuando se encontraba apenas en sus veintitantos, figuraba ya en antologías de poesía latinoamericana junto a nombres consagrados. A partir de entonces, se ha caracterizado por una intensa e infatigable actividad intelectual, literaria y periodística, casi toda ella obsesionada por el transcurrir del tiempo que, de acuerdo con Francisca Noguerol, "se encuentra en la base del concepto de realidad albergado por el poeta" (Noguerol 2009: 42). Es decir, el transcurrir no es para este autor un tema aledaño ni un motivo superficial, sino que se encuentra en el centro de su concepción del mundo y a partir de éste se configura su escritura. En palabras de Julio Trujillo:

A lo largo de cincuenta años y veinte libros, José Emilio Pacheco ha dicho, en esa media voz característica, una y otra vez la misma frase: el tiempo pasa, y no podemos hacer nada al respecto. Toda su prosa y su poesía tienen que ver con esa ecuación de la fugacidad y la impotencia para detenerla. Dicha insistencia es ya una fidelidad, y más: una ética, y esa machaconería resultó ser la fuente de su juventud. En el último cuento de El principio del placer, "Cuando salí de La Habana, válgame Dios", el protagonista, que tomó un barco en Cuba en 1912, llega a Veracruz en 1982, pero esos setenta años fueron para él un trayecto normal de tres o cuatro días. El mundo ha cambiado, él no. ¿Cómo vivir en un tiempo que ya no es suyo? Igual con la obra de Pacheco, que parece recién escrita mientras que todo a su alrededor se ha ido transformando. Nada es suyo porque el Tiempo se lo escamotea. La fórmula parece una condena: para que la obra no caduque, tendrá que atestiguar, siempre, la dolorosa caducidad de todo. (Trujillo y Enrique 2010: 44)

Los ojos de José Emilio Pacheco son de pasión heracliteana y arden con el mundo que se consume ante ellos brillando. En el poema 
"Las ostras" (2000), el autor describe el arte como una atención enfocada, es la mirada que es capaz de registrar el instante y el cambio, aunque ella misma se esté consumiendo y sea, como en "Palabras de Buda" (1963), un "ojo en llamas". A pesar de que esta visión es profundamente coincidente con el aura apocalíptica de la urbe que lo vio nacer, no se debe entender que por eso no existe la plenitud en el mirar de este escritor. De acuerdo con Octavio Paz,

la poesía de José Emilio Pacheco se inscribe no en el mundo de la naturaleza sino en el de la cultura y, dentro de éste en su mitad en sombra. Cada poema de Pacheco es un homenaje al No; Para José Emilio el tiempo es el agente de la destrucción universal y la historia es un paisaje en ruinas. Podría suponerse que este parti pris lo convierte en una suerte de Doctor Pangloss al revés, empeñado en demostrar que vivimos en el peor de los mundos posibles. Por fortuna, no siempre es así. Puesto que todos somos dobles, una y otra vez irrumpe en sus poemas la voz del Sí. (Paz 1987: 13)

Parte de ese "Sí" radica en la aceptación de la fugacidad y en la creencia de la persistencia de la vida a despecho de los seres individuales. Además, en cuanto a su actitud vital, el autor defiende el Carpe diem frente al Fugit irreparabile tempus. El instante se yergue en términos de la intensidad de la vivencia. Otro premio nobel latinoamericano, Mario Vargas Llosa, capta con particular fineza este aspecto de la afirmación de la poesía de Pacheco:

Aislados o fundidos, enmascarados o desnudos, dos temas principales aparecen en todos los poemas [...]. El primero es el descubrimiento del mundo exterior. Frente a los elementos y objetos que le rodean el hombre adquiere la noción de su existencia y, simultáneamente, comprende que la vida tiene un carácter provisional, efímero: las cosas se defienden mejor contra la muerte, son menos perecederas que él. Como estimulada por una especie de horror contra el destino del hombre, que es la extinción, esta poesía se aproxima a las cosas, las invade, quiere instalarse en el corazón de la materia inerte y allí, imitando su inmovilidad y su silencio, conquistar la supervivencia. (Vargas Llosa 1987: 16)

Así, la dialéctica entre la permanencia y la destrucción marca toda la obra de este autor, tanto su poesía como su narrativa y, curiosamente, la obsesión con el tiempo que hace a Pacheco un poeta del instante fugaz lo hace también, de acuerdo con Agnes M. Gullón, un poeta de lugares. José Emilio Pacheco siente la necesidad de enclavar cada instante al sitio que le pertenece; el tiempo pleno y el espacio resultan para él inseparables. De acuerdo con la crítica, a este poeta "su presencia en ese tiempo, en ese lugar, le importa, porque la existencia coordinada de éstos no puede ser sustituida por nada" (Gullón 1987: 124). La esencia del momento y su vida se 
conservan únicamente situando los pensamientos en el sitio en el que se originaron. Así, nos encontramos con que una gran cantidad de sus poemas tienen nombres de lugares. Y Gullón va, acertadamente, todavía más allá, "los poemas, pues, no son reflexiones sino visiones asociadas con lugares que, a su vez, podrían evocar su propio orden de pensamiento" (Gullón 1987: 128). Este autor no trata a los lugares como una referencia concreta sino que, como parte del instante total, en un estrecho diálogo con la analogía romántica que une tiempo, espacio e individuo, se convierten en metáforas profundas.

Y, ejemplos de estas grandes realidades, existen dos inmensidades, dos polos de atracción enormes que se manifiestan en los textos de José Emilio Pacheco desde sus comienzos: la Ciudad de México y el mar.

La pasión por el océano la debe el poeta a las largas temporadas de su juventud pasadas en la costa de Veracruz. El mar y el agua tendrán una carga de eternidad en su obra. Pareciera en ocasiones que en su forma líquida y moldeable, escurridiza, flexible, el agua fuera la única superviviente del incendio que es el mundo.

La ciudad, por el contrario, va a significar el eterno devenir, la eterna destrucción y recreación. El escritor escribe su ciudad en la constante persecución de unas ruinas que se le escapan o desmoronan entre las manos. Un fragmento de "El reposo del fuego" es particularmente significativo en este sentido:

La ciudad en estos años cambió tanto que ya no es mi ciudad, su resonancia

de bóvedas en ecos y sus pasos ya nunca volverán.

Ecos pasos recuerdos destrucciones.

Todo se aleja ya. Presencia tuya, hueca memoria resonando en vano, lugares devastados, yermos, ruinas, donde te vi por último en la noche

de un ayer que me espera en los mañanas

de otro futuro que pasó a la historia,

del hoy continuo en que te estoy perdiendo. (Pacheco 2010: 79)

En la urbe de su nacimiento, José Emilio Pacheco vive la constancia de la transformación y lo descarnado del tiempo, pero también, por instantes, la luminosidad de la hoguera, la forma conseguida y plena que no tiene duración alguna y que le debe precisamente a la tragedia de su existencia pasajera su máxima belleza. Prueba de esto son algunos fragmentos del mismo poema, en los que, precisamente, el fuego parece reposar de su infatigable labor de arrasarlo todo, momentos de plenitud que reaparecerán 
constantemente en la escritura del autor, esos momentos de "Sí" a los que se refería Octavio Paz:

Y entonces de repente,

todo el jardín se yergue entre las piedras:

nace el mundo de nuevo ante mis ojos. (Pacheco 2010: 85)

Si la Ciudad de México tiene el poder de encarnar tanto la vida en su transcurrir mismo -con la feroz e implacable destrucción que reside en él- como el inminente renacimiento del mundo, es quizás porque esta urbe es, en mucho, el universo en el que está arraigado el poeta, y en él proyecta los valores cósmicos. Además, dado que la ciudad es un universo creado por el hombre, en ella también se vierte la visión que Pacheco tiene de la condición humana y de sí mismo. Su presencia y sus espacios son, así, un detonador de observaciones metafísicas y ontológicas de diversas índoles y tonos, además del pretexto para desplegar sus recuerdos, sus nostalgias, sus deseos.

Para poder estudiar estas imágenes y reflexiones que la Ciudad de México ha despertado en José Emilio Pacheco -fuertemente ligadas a los mitos fundacionales de la urbe y a la manera en la que ha sido constituida- a lo largo de su trayectoria como autor, me centraré, sobre todo, en su obra poética que representa, sin lugar a dudas, su escritura literaria más significativa en este sentido. $Y$, para los fines que interesan a este artículo, recurriré, sobre todo, a la relación que el autor entabla con el agua de la metrópoli y sus diversos significados.

La Ciudad de México sostiene una relación muy complicada con el agua que la habita y con la que la habitó en el pasado. Este líquido es una de las fuentes más prolíficas de significados, imágenes, sentidos, contradicciones y fantasmas de la urbe. No cabe duda que adentrarnos en este aspecto desde el punto de vista de uno de los autores que más profundamente conoce y ama a esta ciudad, arrojará luces singulares tanto sobre el imaginario del sitio como sobre la obra del escritor.

No podemos olvidar que la Ciudad de México en sus orígenes fue una ciudad acuática, cimentada en el centro de una cuenca lacustre y surcada por canales y acequias, además de numerosos ríos. La urbe, a partir de la llegada de los españoles y en aras de la modernidad, ha ido perdiendo poco a poco la visibilidad de esta agua: ha visto sus acequias desecadas, sus fondos lacustres drenados y sus ríos intubados. Sin embargo, la relación que la metrópoli guarda con el agua en la memoria y en sus subterráneos se ve reflejada en la escritura de Pacheco en las concordancias que la hace establecer con la propia historia y permanencia. La ciudad de la infancia y juventud de este poeta todavía tenía ríos, en algo aún recordaba a esa ciudad de agua de sus nostalgias y sus pesadillas que subyacerá siempre, a 
manera de un fantasma casi siniestro, a la ciudad seca de tiempos posteriores.

Como mencionábamos anteriormente, el agua -como el martiene en la escritura de José Emilio Pacheco un significado de eternidad. En ella reside el ciclo de la vida, el eterno retorno del tiempo. En su filtrarse en la tierra, evaporarse en el cielo, formar parte de los cuerpos y retornar al ambiente, José Emilio Pacheco ve la persistencia de la vida y su curso sobre lo circunstancial y lo humano, que está condenado a la destrucción.

Por esta razón, la imagen del agua en la Ciudad de México es altamente significativa, pues representa la presencia de lo eterno que resulta, la mayor parte de las veces que Pacheco hace alusión a ella, aniquilado por la urbe misma. Sobre el río, Rocío Peñalta Catalán afirma: "En ocasiones, este cauce de agua se convierte en el elemento más significativo y definitorio de una ciudad" (Peñalta Catalán 2010: 35). Podemos imaginar lo que hacen a una urbe decenas de ríos enterrados, fantasmas, y una inmensa laguna desaparecida. El agua es la vida de la ciudad y en este caso es vida abundante, pero oculta, acaso pervertida o invertida. Podemos prefigurar en nuestras mentes uno de los elementos que da a la Ciudad de México su calidad de urbe post-apocalíptica en el imaginario de tantos autores e, incluso, de sus ciudadanos.

Desde otro punto de vista, Roland Barthes afirma que las ciudades que carecen de costa o de la presencia de un río, lago o cualquier otro cuerpo acuático suelen obstaculizar la adaptación de sus habitantes; de acuerdo con él, estas urbes "ofrecen mayor resistencia a la significación [...]; presentan dificultades de vida, de legibilidad" (Barthes 1993: 265). De nuevo, la presencia fantasmagórica del agua en la Ciudad de México la pone en un impasse de significación. Podría ser una ciudad en la que se fluyera literalmente- $y$, sin embargo, la supresión de sus aguas la vuelve difícil y huraña. Si algo tiene esta complicada metrópoli es una resistencia a ser una sola y a dirigirse hacia un significado. Tiene una reticencia a ser leída e, incluso, habitada y quizá deba algunos de estos signos al destino de sus aguas.

Ya se deja ver mucho de esto en "El reposo del fuego", uno de los poemas contenidos en Los elementos de la noche, directamente heredero de poemas densos y filosóficos como "Piedra de sol" de Octavio Paz o de "Muerte sin fin" de José Gorostiza. En él se trasluce el gran impacto que tiene el agua en la visión de la urbe de José Emilio Pacheco:

Aquí te expandes, vida mortal, color de sangre, dicha

de tenerte un instante que no vuelve.

Tu reino es la ciudad de agua y aceite 
que flotan sin unirse. Su equilibrio es su feroz tensión. Y su combate

se disfraza de paz y tregua alerta. (Pacheco 2010: 62)

La estrofa tiene una alta densidad significativa pues, en primer lugar, se establece que el lugar de expansión -y de ser, por un dichoso instante- de la vida mortal, su reino, es la "ciudad de agua y aceite". El aceite, como opuesto del agua, que jamás puede mezclarse con ella, representa la combustión de la vida urbana, su ser una hoguera que se consume y, a la vez, significa las cosas hechas por el hombre, la tecnología contaminante. Se opone al agua en cuanto a que representa las cosas fugaces y humanas, pero, además, en su carácter artificial, comparado con el natural del líquido vital. Así, Pacheco encumbra la urbe como al sitio de la vida y a ésta la define como una "feroz tensión" entre lo eterno y lo pasajero, lo puro y lo contaminado, lo natural y lo humano. El poema, que es particularmente denso y elocuente en cuanto a los significados que la Ciudad de México tiene para José Emilio Pacheco, insiste sobre la presencia acuática, esta vez partiendo desde el sentido del olfato y haciéndolo corresponder con el de la vista:

Brusco olor del azufre repentino color verde del agua bajo el suelo.

Bajo el suelo de México se pudren

todavía las aguas del diluvio.

Nos empantana el lago, sus arenas

movedizas atrapan y clausuran

la posible salida.

Lago muerto en su féretro de piedra.

Sol de contradicción.

(Hubo dos aguas

y en la mitad una isla.

En frente un muro

a fin de que la sal no envenenara

nuestra laguna dulce en la que el mito

abre las alas todavía, devora

la serpiente metálica, nacida

en las ruinas del águila. Su cuerpo

vibra en el aire y recomienza siempre). (Pacheco 2010: 77)

El espacio que se describe es el subsuelo, un casi no-espacio, desde donde parte, sin embargo, un olor a azufre -asociado culturalmente al infierno- que emana de un agua verde que descansa debajo de la tierra: el agua de la vieja ciudad prehispánica. Estas aguas, como un antiguo fantasma, como un muerto eternamente vivo que jamás cesa su putrefacción y decadencia, asedian la ciudad nueva, "empantanan" a los habitantes, los "atrapan" en sus "arenas movedizas", "clausuran la posible salida". Es una constante en la 
literatura encontrar a la Ciudad de México como un espacio del que no se puede salir y Pacheco explica este sentimiento con una imagen escabrosa, la de las aguas antiguas bloqueando la salida de sus habitantes, como queriendo cobrarse así su desaparición. El agua del subsuelo es el pasado, la memoria indestructible que reclama la violencia con la que fue sepultada viva.

El poema continúa con el endecasílabo "Lago muerto en su féretro de piedra", afirmando las intuiciones del lector sobre la presencia activa y siniestra de un muerto enterrado en la oscuridad $y$, sin embargo, a esta imagen de lúgubre enclaustramiento, sigue un luminoso heptasílabo contrastante que en sí mismo lleva la palabra de su función: "Sol de contradicción". Pacheco nos recuerda que la ciudad es el lugar de lucha entre la vida y la muerte y que la segunda no tiene todo ganado. Esa oscuridad tremebunda también relumbra en una contradicción diáfana. Enseguida, dentro de un paréntesis, como si se tratara de una explicación de este repentino fulgor, el poeta introduce el recuerdo de la vida anterior de esa agua enclaustrada; nos cuenta que existieron una laguna de agua salada y otra de agua dulce separadas por un muro, y que en la laguna de agua dulce había una isla en la que se representó el mito fundacional de la Ciudad de México: el hallazgo por parte de los aztecas de un águila sobre un nopal devorando una serpiente. Sin embargo, la interpretación de Pacheco de este mito vuelve a recalcar el aspecto de la eterna lucha entre la vida y la muerte que parece ser para él el fondo último de su urbe natal. El poeta nos describe un mito eterno, que todavía abre las alas, vivo, y es él quien devora a una serpiente metálica, nacida de las ruinas del águila. Se trata de una imagen alucinantemente circular en la que el cuerpo de la serpiente, que "vibra en el aire y recomienza siempre" pareciera brotar -y ser a la par devorada por ella- de un águila en decadencia que, al mismo tiempo, sin embargo, le otorga sus alas al conjunto. Además, esta serpiente metálica y eternamente móvil representa a la ciudad moderna e hirviente, que nace de las ruinas de la ciudad azteca, que le da aliento con su espíritu. Así, es la metrópolis, alimentada de la vida y la muerte, nacida de y eterna representante del mismo mito de generación y destrucción, quien se yergue, luminoso "sol de contradicción", desde la profundidad oscura de sus aguas.

Esta luminosidad que emerge de las aguas profundas nos hace pensar que, como contraparte a su carácter mortuorio, también tienen algo de materno y uterino. El lago siempre ha sido un símbolo de maternidad, cuánto más si se encuentra bajo tierra. Así, en la literatura de José Emilio Pacheco, las aguas cumplen el ciclo vital, abarcan la muerte y el nacimiento y en su devenir son eternas. Esto coincide con la descripción que hace, en este caso del río, Rocío Peñalta Catalán, del cual dice que "es un símbolo ambivalente. Por una parte representa la fuerza creadora de la naturaleza, está en el 
origen de la vida, refleja la fertilidad de la tierra. Por otro lado, simboliza el paso del tiempo, el transcurso irreversible de la vida y del olvido" (Peñalta Catalán 2010: 38).

Más adelante en el poema, José Emilio Pacheco insiste en la cualidad absolutamente contradictoria de la ciudad, de la existencia del hombre, por añadidura, y profundiza en ella:

Bajo el suelo de México verdean eternamente pútridas las aguas que lavaron la sangre conquistada.

Nuestra contradicción -agua y aceitepermanece a la orilla y aún divide, como un segundo dios todas las cosas:

lo que deseamos ser y lo que somos. (Pacheco 2010: 78)

La primera imagen es hermosa por su inmensa capacidad de síntesis. Las aguas que anteriormente nos habían aparecido muertas y sepultadas, ahora se nos revelan, además, no sólo como aquellas de la ciudad prehispánica, sino, en un mayor protagonismo, como las que "lavaron la sangre conquistada". Son agua, pero también son sangre, recuerdo de muerte $y$, a la vez, redención. No conforme con esto, ahora "verdean". Si bien, esa cualidad se corresponde con su putridez, el uso del verbo "verdear" las emparenta directamente con un jardín que renace. Además, si las aguas son "eternamente pútridas", son, en principio, eternas. La sangre conquistada muere y renace en una espiral vertiginosa. Así, Pacheco juega con las palabras y nos muestra su cosmovisión, en la que la vida perennemente se sustenta en la muerte y en la destrucción. Como en Heráclito, el devenir es la única constante.

La contradicción "agua y aceite" es enaltecida al papel de "segundo dios". Esto, sin duda no es casual. Es el poeta que nos señala el meollo de su obra, la violenta bivalencia en la que se sustenta y que se repite obsesivamente en fondo y en forma. Y la tensión de ese encuentro constante de contrarios es la razón por la cual las aguas de la Ciudad de México son tratadas como un espíritu que no ha obtenido descanso, que necesita una paz que no conseguirá nunca.

Un texto escrito muchos años más tarde, "A la extranjera" (2009), toca el tema del Río Magdalena, uno de los ríos de la urbe que más ha resistido en el tiempo, pero que se ha visto cada vez más asediado por el crecimiento desmedido, la contaminación de sus aguas y drásticamente marginado por el paisaje urbano:

En los bosques de Viena usted me dio a probar el vino recién nacido y me dijo: "La Ciudad de México también fue parte del imperio habsbúrgico. Por tanto, más que un Schönbrunn o un Belvedere, 
tendríamos la obligación de regalarle un poco del Danubio. En la cuenca lacustre sólo quedan el Lago de Xochimilco y el triste Río Magdalena. A fines del XIX un violinista pobre de veintiún años le compuso al Magdalena, quién lo diría, Sobre las olas, el mejor vals vienés del mundo. Lo digo como austríaca".

A usted le duele esta ciudad que también ha hecho suya y lamenta ver cómo la hemos destruido y seguimos arrasando. No entiendo sus razones para amar un sitio desesperante y sin esperanza. $O$ tal vez existe la esperanza porque usted se encuentra aquí una vez más y llena de luz otra estación sombría.

Nací en un lugar que se llamaba como éste y ocupaba su espacio. Ahora también en mi suelo natal soy extranjero en tierra extraña. Ya no conozco a nadie ni reconozco nada. Usted, en cambio, no es extranjera en ningún lado. Usted es de todas partes como la música.

Por favor no se vaya. No se lleve al partir un fragmento de luz entre el desierto pardo y la barbarie que por codicia y estupidez hemos engendrado. (Pacheco 2010: 752)

En primer lugar, podemos darnos cuenta de que este texto es un digno heredero del romanticismo no solamente en cuanto a su exploración del poema en prosa, sino también en lo referente a su temática. La interlocutora del yo lírico, la extranjera, es un personaje proveniente de la simbología utilizada por autores como Novalis o el propio Baudelaire, a quien tantos homenajes rinde Pacheco con su escritura. En la obra de estos autores, esta figura representa a un ser superior al resto, con mayores capacidades perceptivas, mayor sensibilidad e investido de un aura sagrada que incluso colinda con el misticismo. El extranjero, y particularmente la extranjera -dotada ésta de un aura de erotismo-, suele ser una representación de la Otredad, de esa parte del universo que se nos escapa, que no es nuestra, en palabras de Octavio Paz, de la "otra orilla", que nos llama con su seducción a dar un salto hacia ella para, realmente, devolvernos a nosotros mismos:

En suma, el "salto mortal", la experiencia de "la otra orilla", implica un cambio de naturaleza: es un morir y un nacer. Mas "la otra orilla" está en nosotros mismos. Sin movernos, quietos, nos sentimos arrastrados, movidos por un gran viento que nos echa fuera de nosotros. Nos echa fuera y, al mismo tiempo, nos empuja hacia dentro de nosotros. La metáfora del soplo se presenta una y otra vez en los grandes textos religiosos de todas las culturas: el hombre es desarraigado como un árbol y arrojado hacia allá, a la otra orilla, al encuentro de sí. (Paz 2008: 122-123)

José Emilio Pacheco vuelve a hacer gala de la complejidad de sus imágenes. La extranjera, una especie de ser mítico sin nombre que reaparecerá en otros textos con orígenes inciertos y distintos, introduce en el yo lírico la imagen de su ciudad a través de un trago 
de vino Schönbrunn y le recuerda que alguna vez aquella urbe perteneció al imperio habsbúrguico; es decir, la mujer convierte, de pronto, la tierra natal del poeta en otredad, en una tierra ajena e idílica que se anhela en la distancia. La imagen melancólica que la extranjera pinta de la ciudad es acuática; es la "cuenca lacustre" en la que en estos tiempos sólo quedan el Lago de Xochimilco y "el triste Río Magdalena". Y la visión del agua comenzada con un sorbo de vino revienta en música cuando la mujer relata que a este río "un violinista pobre de 21 años" le compuso "Sobre las olas, el mejor vals vienés del mundo". Esta vez no es una nostalgia azteca, sino curiosamente vienesa la que cubre la Ciudad de México. Otro tiempo perdido, que jamás volverá y que se refleja en la fantasmagoría de las aguas, que flotan en notas musicales imperecederas, pero desaparecen ante la vista.

El sujeto lírico responde a la extranjera que puede ver el dolor que esta ciudad, suya también ahora, le causa. Y manifiesta su asombro ante este amor por un lugar "desesperante y sin esperanza", aunque es evidente que él comparte el amor por esta urbe un poco suya y un poco extranjera -siempre completa en la lejanía y nunca en el presente- a la que el amor y la luminosa presencia de la forastera devuelven, de alguna forma, la confianza.

También en este fragmento encontramos una dicotomía. La ciudad es propia y extranjera, el sujeto lírico la siente suya y, a la vez, se siente ajeno a ella. Es una con su yo y es alteridad. Y la nota de la alteridad es que es siempre "la otra orilla", el mundo lejano que llama al sujeto incompleto y fragmentado para sentirse uno. Cito nuevamente a este respecto a Octavio Paz:

Ese Otro también es yo. La fascinación sería inexplicable si el horror ante la otredad no estuviese, desde su raíz, teñido por la sospecha de nuestra final identidad con aquello que de tal manera nos parece extraño y ajeno. [...] La experiencia de lo Otro culmina en la experiencia de la Unidad. (Paz 2008: 133)

Así, José Emilio Pacheco combina un sentimiento de dolorosa pertenencia con otro de anhelante desarraigo, deseando formar parte de una ciudad que existe en la idealidad, en la lejanía, y rechazando la ciudad real que se consume con el tiempo y le parece monstruosa. Es un constante desgarrarse del sujeto lírico, una eterna "incompletud" que se manifiesta en la cruz -mejor dicho aquí que nunca- que forman el espacio y el tiempo, enclavándolo en su muerte.

Un fragmento que es certero en señalar la eterna frustración del ser que parece vivirse en la Ciudad de México de acuerdo con este poeta y que trata un espacio acuático es el texto "Acrosoma": 
En la ciudad para siempre a medio hacer, para siempre a medio destruir, abundaban en aquel tiempo los terrenos baldíos, reinos del cempasúchil y el pirú, la flor azteca y el árbol quechua, inermes ante la tempestad del progreso. El asfalto y los edificios avanzaban sobre tierras que hasta ayer habían sido campos y haciendas. La estación de las lluvias dejaba pozas habitadas por seres destinados a no alcanzar la edad adulta. (Pacheco 2010: 756)

El escritor nos pinta un paisaje de expansión urbana. Una vez más nos topamos con la oposición entre lo natural y lo producido por el hombre, entre lo prehispánico-originario (los árboles y las flores son quechuas y aztecas) y lo posterior. Parece que justamente este estado intermedio, de transición entre ambos puntos, produce las charcas en donde viven los renacuajos o ajolotes a los que Pacheco llama acrosomas comparándolos con espermatozoides, células genésicas, que nunca cumplirán un destino, seres que "nunca alcanzarán la edad adulta" porque morirán antes. Su destino es ser incompletos, como el autor vive a la urbe, a sus habitantes $y$, por ende, a sí mismo.

Una última imagen compara a la Ciudad de México con un despeñadero por medio de sus aguas. Nos dice el poeta en "La casa": "La Ciudad de México es el otro Cañón del Sumidero: sus aguas jamás devuelven lo que se precipita a sus abismos" (Pacheco 2010: 771).

Así, identificada con una inmensidad terrible, mas de gran hermosura, que devora todo cuanto cae en ella -pero lo acumula en la eternidad de sus aguas-, la Ciudad de México se yergue como el escenario del acaecer del tiempo y sus estragos, hecho que le confiere la cualidad del horror $y$, sin embargo, al mismo tiempo, nos deslumbra con una belleza que se guarda en sus líquidos fantasmas.

De esta manera, a través de la obra de José Emilio Pacheco que no es, ni por asomo, el único autor que se aproxima a esta temática aunque sí uno de los más profundos y de mayor calidad literaria- podemos observar la gran variedad de significados, muchos de ellos desplazados del clásico simbolismo que el agua tiene para una ciudad e incluso subvertidos o revertidos, con los que decenas de ríos sepultados y una laguna desaparecida dotan a una urbe de por sí caótica, difícil e intrincada en todas sus capas, concretas e imaginarias, de existencia. El agua es quizá el primer manantial de donde emerge la complicación esencial de la Ciudad de México y resulta muy interesante observar de qué manera un autor profundamente identificado con la ciudad en la que nació se apropia de esta complicación, y expresa a través de imágenes acuáticas emanadas de ella sus principales angustias y consideraciones metafísicas y ontológicas; a través de la subjetividad de Pacheco, 
emerge, curiosamente, la voz de una ciudad, se hacen tangibles los espectros guardados en su subsuelo.

\section{Bibliografía}

BARTHES, Roland (1993): "Semiología y urbanismo", en La aventura semiológica. Barcelona: Paidós.

GULLÓN, Agnes M. (1987): "Sueños y distancia en la poesía de José Emilio Pacheco", en Hugo J. Verani (ed.), La hoguera y el viento. José Emilio Pacheco ante la crítica. México: Universidad Autónoma Metropolitana, col. Cultura Universitaria.

NOGUEROL, Francisca (2009): "Leerse en Pacheco (Introducción)", en José Emilio Pacheco, Contraelegía. Salamanca: Ediciones Universidad de Salamanca.

PACHECO, José Emilio (2010): Tarde o temprano. México: Tusquets.

PAZ, Octavio (1987): "Cultura y natura", en Hugo J. Verani (ed.), La Hoguera y el viento. José Emilio Pacheco ante la crítica. México: Universidad Autónoma Metropolitana, col. Cultura Universitaria.

- (2008): El arco y la lira. México: FCE.

PEÑALTA CATALÁN, Rocío (2010): "Un elemento de la naturaleza en el paisaje urbano: el río", en Eugenia Popeanga (coord.), Ciudad en obras. Metáforas de lo urbano en la literatura y las artes. Berna: Peter Lang.

TRUJILLO, Julio; y ENRIQUE, Álvaro (2010): "José Emilio Pacheco". Letras Libres, año 12, núm. 133, p. 44.

VARGAS LLOSA, Mario (1987): "La poesía de José Emilio Pacheco", en Hugo J. Verani (ed.), La Hoguera y el viento. José Emilio Pacheco ante la crítica. México: Universidad Autónoma Metropolitana, col. Cultura Universitaria. 